\title{
Normothermia does not improve postoperative hemostasis nor does it reduce inflammatory activation in patients undergoing primary isolated coronary artery bypass
}

\author{
Mario Gaudino, $\mathrm{MD}^{\mathrm{a}}$ \\ Roberto Zamparelli, MD ${ }^{\mathrm{b}}$ \\ Felicita Andreotti, MD ${ }^{\mathrm{c}}$ \\ Francesco Burzotta, MD \\ Licia lacoviello, $\mathrm{MD}^{\mathrm{d}}$ \\ Franco Glieca, MD \\ Maria Benedetta Donati ${ }^{\mathrm{d}}$ \\ Attilio Maseri, MDc \\ Rocco Schiavello, MD ${ }^{\mathrm{b}}$ \\ Gianfederico Possati, MD
}

From the Departments of Cardiac Surgery, Cardiac Anaesthesiology, ${ }^{\mathrm{b}}$ and Cardiology, ${ }^{\mathrm{c}}$ Catholic University, Rome, and "Angela Valenti" Laboratory of Genetic and Enviromental Risk Factors for Thrombotic Disease, ${ }^{\mathrm{d}}$ Department of Vascular Medicine and Pharmacology, Consorzio Mario Negri Sud, Santa Maria Imbaro, Italy.

Received for publication April 26, 2001; revisions requested June 13, 2001; revisions received Sept 26, 2001; accepted for publication Oct 3, 2001.

Address for reprints: Mario Gaudino, MD, Divisione di Cardiochirurgia, Policlinico Universitario A. Gemelli, Largo A. Gemelli 8, 00168 Rome, Italy (E-mail: mgaudino@ tiscalinet.it)

J Thorac Cardiovasc Surg 2002;123: 1092-100

Copyright () 2002 by The American Association for Thoracic Surgery

$0022-5223 / 2002 \$ 35.00+0 \quad \mathbf{1 2 / 1 / 1 2 0 7 0 9}$

doi:10.1067/mtc.2002.120709
Background: Despite its common acceptance in clinical practice, the effective benefits of normothermic systemic perfusion during coronary artery bypass operations are far from established.

Methods: A total of 113 patients undergoing primary isolated coronary artery bypass were randomly assigned to normothermic $\left(37^{\circ} \mathrm{C}\right)$ or hypothermic $\left(26^{\circ} \mathrm{C}\right)$ systemic perfusion. The clinical course of the patients was prospectively recorded, and several inflammatory and fibrinolytic markers (C-reactive protein, fibrinogen, interleukin 6, plasminogen activator inhibitor 1 , prothrombin time, activated partial thromboplastin time, platelets, and white blood cell counts) were determined before surgical intervention; 24, 48, and 72 hours thereafter; and at hospital discharge.

Results: Postoperatively, 2 in-hospital deaths occurred in the normothermic series and none in the hypothermic series. Four patients had a myocardial infarction, 1 had respiratory insufficiency, 1 had to be reoperated on for graft malfunction, and none had renal insufficiency in the hypothermic group versus 1 patient with each of these complications in the normothermic series. Mean blood loss in the first 24 hours was $766 \pm 223 \mathrm{~mL}$ in the normothermic group and $740 \pm 220 \mathrm{~mL}$ in the hypothermic group. None of these differences was statistically significant. Similarly, no significant difference in the postoperative level of any of the measured variables at any time point was evident between the patients in the normothermic and hypothermic groups.

Conclusion: Normothermic systemic perfusion does not influence the clinical course or the extent of inflammatory and hemostatic activation in patients undergoing primary isolated coronary artery bypass.

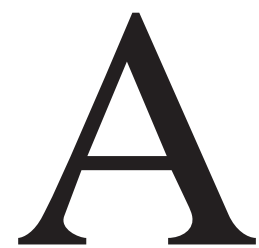

lthough, in recent years, normothermic cardiopulmonary bypass (CPB) has often been adopted in common practice, its effective benefits are far from established. Theoretically, normothermic systemic perfusion (NSP) should reduce the extent of activation of the inflammatory system and maintain a better cellular homeostatic function and thus minimize the post-CPB systemic syndrome. ${ }^{1}$ However, this theoretic assumption is, at present, supported by little objective evidence. 
TABLE 1. Patient's preoperative characteristics in the entire group and in relation to the CPB temperature used at surgical intervention

\begin{tabular}{|c|c|c|c|c|}
\hline & Overall & $\begin{array}{l}\text { Normothermic } \\
\text { group }\end{array}$ & $\begin{array}{l}\text { Hypothermic } \\
\text { group }\end{array}$ & $P$ value* \\
\hline No. of patients & 113 & 55 & 58 & - \\
\hline Male/female ratio & $105 / 8$ & $52 / 3$ & $53 / 5$ & .51 \\
\hline \multicolumn{5}{|l|}{ Cardiac risk factors } \\
\hline Diabetes & 23 & 13 & 10 & .36 \\
\hline Smoking & 45 & 19 & 26 & .19 \\
\hline Dislipemia & 30 & 19 & 11 & .06 \\
\hline Hypertension & 71 & 31 & 40 & .20 \\
\hline Family history of CAD & 34 & 18 & 16 & .85 \\
\hline Previous MI & 57 & 24 & 33 & .08 \\
\hline Left main disease & 11 & 7 & 4 & .29 \\
\hline Heart failure & 5 & 3 & 2 & .63 \\
\hline Ejection fraction $<0.50$ & 29 & 15 & 14 & .70 \\
\hline
\end{tabular}

$C A D$, Coronary artery disease; $M I$, myocardial infarction; $E F$, ejection fraction.

* Between normothermic and hypothermic groups.

This prospective randomized investigation was conceived to elucidate the effect of $\mathrm{CPB}$ temperature on the postoperative activation of the hemostatic and inflammatory systems in patients submitted to isolated coronary artery bypass procedures by using both clinical and hematic indexes.

\section{Patients and Methods}

\section{Patient Population}

On approval of the Ethics Committee of the Catholic University, a prospective study on the effect of CPB temperature on postoperative hemostatic and inflammatory activation in patients undergoing coronary artery bypass grafting $(\mathrm{CABG})$ was started in January 1998 (Fibrinolisi e Infiammazione nella Fase Acuta: FIFA study).

From this date on, all patients scheduled to undergo isolated elective CABG at our center were screened. Rigorous exclusion criteria were adopted to maximize homogeneity and comparability between groups: Patients with associated cardiac or noncardiac surgical procedures, age greater than 80 years, single-vessel disease, emergency or urgent revascularization, left ventricular ejection fraction of less than 0.30 , carotid artery disease, previous cerebrovascular accident, chronic dialysis, hepatic failure, respiratory or renal insufficiency, hemorrhagic conditions, active infection, and chronic anti-inflammatory therapy were all excluded from the study. Only patients operated on between 8 and $10 \mathrm{AM}$ were considered to rule out possible confounding effects of circadian variability. After enrollment, patients were randomly assigned to be operated on with normothermic versus hypothermic CPB. (We adopted a 1:1 randomization according to a computer-generated random series of numbers.)

All patients gave their consent to participate in the protocol.

Data collection ended in May 1999, and a total of 113 patients were included.

\section{Surgical Technique}

After median sternotomy, CPB was instituted in standard fashion by cannulating the right atrium and the ascending aorta. For anticoagulation, an intravenous bolus of heparin (300 IU $/ \mathrm{kg}$ ) was followed by boluses of $100 \mathrm{IU} / \mathrm{kg}$ to maintain activated clotting times of longer than 400 seconds.

During $\mathrm{CPB}$, the nasopharyngeal temperature was kept at $37^{\circ} \mathrm{C}$ in the normothermic group (patients were actively rewarmed if their nasopharyngeal temperature fell below $34^{\circ} \mathrm{C}$ ) and at $26^{\circ} \mathrm{C}$ in the hypothermic series. Myocardial protection was always accomplished by means of anterograde isothermic intermittent blood cardioplegia.

The left internal thoracic artery was used to graft the left anterior descending coronary artery, and other venous or arterial conduits were used for the remaining target coronary vessels. At the end of $\mathrm{CPB}$, anticoagulation was reversed with protamine sulfate (1-1.5 mg per $100 \mathrm{IU}$ of heparin).

\section{Samples and Assays}

Blood samples were collected immediately before surgical intervention; 24, 48, and 72 hours thereafter; and at hospital discharge. The samples were collected in trisodium citrate $(0.106 \mathrm{~mol} / \mathrm{L})$ and centrifuged without delay at $3000 \mathrm{~g}$ and $4^{\circ} \mathrm{C}$ for 20 minutes. Plasma was stored at $-80^{\circ} \mathrm{C}$ within 1 hour of sampling, and cellular pellets were kept at $-20^{\circ} \mathrm{C}$.

The plasma concentrations of the following factors were measured in a core laboratory blinded to the patients' status: C-reactive protein (CRP) was measured by using the nephelometric method (APS; Beckman, Palo Alto, Calif); plasma fibrinogen concentrations were assayed by using the modified Clauss functional method (Instrumentation Laboratory SpA, Milan, Italy); interleukin (IL) 6 levels were analyzed by using the IL-6 Human Biotrak Elisa System (Amersham Pharmacia Biotech, Monza, Italy).

Plasminogen activator inhibitor 1 (PAI-1) antigen levels were determined by means of double-antibody sandwich enzyme-linked immunosorbent assay (Instrumentation Laboratory SpA). This marker was chosen to assess the fibrinolytic capacity of plasma because it rapidly, irreversibly, and specifically inhibits both tissue-type and urokinase-type plasminogen activator. ${ }^{2}$

Measurement of prothrombin time (expressed as international normalized ratio [INR]), activated partial thromboplastin time 
TABLE 2. Operative data in the entire group and in relation to the CPB temperature used at surgical intervention

\begin{tabular}{|c|c|c|c|c|}
\hline & Overall & $\begin{array}{c}\text { Normothermic } \\
\text { group }\end{array}$ & $\begin{array}{c}\text { Hypothermic } \\
\text { group }\end{array}$ & $P$ value* \\
\hline CPB time (min) & $75 \pm 21$ & $74.5 \pm 18.3$ & $87.5 \pm 21.7$ & .12 \\
\hline Crossclamp time (min) & $62 \pm 18$ & $62.1 \pm 16.0$ & $73.3 \pm 19.1$ & .71 \\
\hline \multicolumn{5}{|l|}{ Grafts/patient } \\
\hline 2 & 22 & 11 & 11 & .92 \\
\hline 3 & 56 & 29 & 27 & .87 \\
\hline 4 & 30 & 13 & 17 & .63 \\
\hline 5 & 5 & 1 & 4 & .39 \\
\hline
\end{tabular}

* Between normothermic and hypothermic groups.

TABLE 3. Postoperative mortality and morbidity in the entire series and in relation to the CPB temperature used at surgical intervention

\begin{tabular}{|c|c|c|c|c|}
\hline & Overall & $\begin{array}{c}\text { Normothermic } \\
\text { group }\end{array}$ & $\begin{array}{l}\text { Hypothermic } \\
\text { group }\end{array}$ & $P$ value* \\
\hline Death & 2 & 2 & 0 & .14 \\
\hline Stroke & 0 & 0 & 0 & - \\
\hline $\mathrm{Ml}$ & 5 & 1 & 4 & .18 \\
\hline Sepsis & 1 & 0 & 1 & .32 \\
\hline Shock & 1 & 0 & 1 & .32 \\
\hline Renal insufficiency & 1 & 1 & 0 & .30 \\
\hline Respiratory insufficiency & 2 & 1 & 1 & .97 \\
\hline Ventilation $>24 \mathrm{~h}$ & 9 & 4 & 5 & .79 \\
\hline Reoperation & 2 & 1 & 1 & .97 \\
\hline Postoperative bleeding $(\mathrm{mL} / 24 \mathrm{~h})$ & $753 \pm 218$ & $766 \pm 223$ & $740 \pm 220$ & .53 \\
\hline Revision for bleeding & 8 & 3 & 5 & .51 \\
\hline Atrial fibrillation & 24 & 11 & 13 & .95 \\
\hline Need for blood transfusion & 28 & 10 & 18 & .11 \\
\hline Major complications & 6 & 2 & 4 & .44 \\
\hline Minor complications & 37 & 15 & 22 & .22 \\
\hline Hemorrhagic complications & 31 & 12 & 19 & .19 \\
\hline Any complication & $38 \dagger$ & 15 & 23 & .16 \\
\hline Mean ICU stay (d) & $2.0 \pm 2.7$ & $1.6 \pm 0.9$ & $2.1 \pm 3.3$ & .27 \\
\hline Mean postoperative stay (d) & $6.1 \pm 3.2$ & $5.6 \pm 1.4$ & $6.3 \pm 3.9$ & .22 \\
\hline
\end{tabular}

MI, Myocardial infarction.

*Between normothermic and hypothermic groups.

tFive patients had both major and minor complications.

(PTT), and platelet, white blood cell (WBC), neutrophil, lymphocyte, and monocyte counts was performed in the hospital laboratory and was used also for clinical purposes in the management of patients after the intervention (see Appendix).

\section{Statistical Analysis}

The $\chi^{2}$ or Fisher exact test was used to compare discrete variables. Correlations were assessed by using the Pearson or Spearman methods. Continuous variables (presented as means $\pm \mathrm{SD}$ ) were compared by means of parametric or nonparametric (KruskalWallis) analysis of variance. Repeated-measures multivariate analysis of variance (GLM procedure for SAS) was used to assess changes in levels of the different parameters over time in the overall population and according to the CPB temperature. Analyses were carried out with the SAS statistical package.

\section{Results}

The preoperative features of the patients are shown in Table 1. Normothermic and hypothermic groups did not differ significantly in age, sex, major coronary risk factors, previous myocardial infarction, history of congestive heart failure, and angiographic characteristics.

\section{Operative Data}

Operative results are given in Table 2. No significant differences in CPB and aortic crossclamp times or number of grafts per patient were noted between the normothermic and hypothermic series.

\section{Clinical Results}

The postoperative course of the 113 patients is summarized in Table 3. Two in-hospital deaths occurred in the normo- 

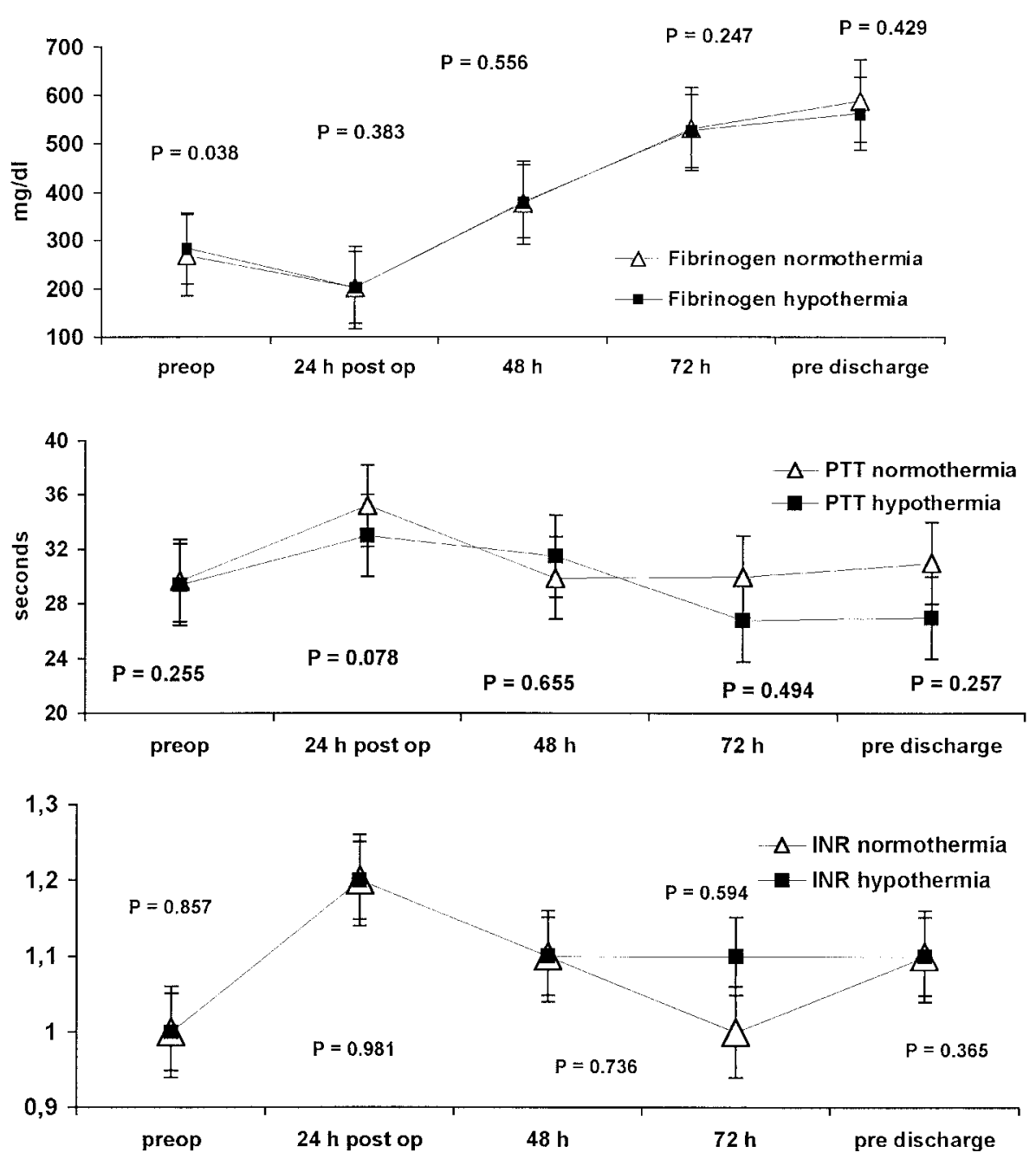

Figure 1. Indexes of coagulation in the normothermic versus hypothermic series at the different sampling intervals.

thermic series as a result of massive pulmonary embolism (on the third postoperative day) and myocardial infarction (8 days after the operation). Postoperatively, 5 patients experienced myocardial infarction, 2 had respiratory insufficiency, 1 had renal insufficiency, 1 had a septic syndrome, and 2 had to be reoperated on for clinical and instrumental evidence of graft malfunction. Eight patients needed a surgical revision of the hemostasis, and 28 needed at least one postoperative blood transfusion. Overall, 38 patients experienced at least 1 postoperative complication (6 major and 37 minor), and 31 had hemorrhagic complications.

Mean stay in the intensive care unit (ICU) and in-hospital stay after the operation were $2.0 \pm 2.7$ and $6.1 \pm 3.2$ days, respectively.

No significant differences in mortality and type and incidence of postoperative complications were found between patients operated on with normothermic CPB versus those operated on with hypothermic CPB (Table 3). In the hypothermic series postoperative myocardial infarction and need for blood products occurred slightly more frequently (leading to a greater incidence of minor and hemorrhagic complications in this series), but these differences did not reach statistical significance. Mean blood loss did not significantly differ between the 2 subgroups.

Similarly, the mean stay in the ICU and in-hospital stay after the operation were similar between the 2 groups (although slightly superior among hypothermic patients).

\section{Markers of Hemostatic and Inflammatory Activity}

Both hemostatic and inflammatory markers changed significantly in the postoperative period: IL- 6 and WBC, neutrophil, monocyte, and lymphocyte counts peaked in the first hours after the operation. CRP levels peaked at 72 hours and remained elevated at discharge, whereas platelet levels were greatly reduced 48 hours after the operation and returned to normal values at the time of discharge. Mean fibrinogen 

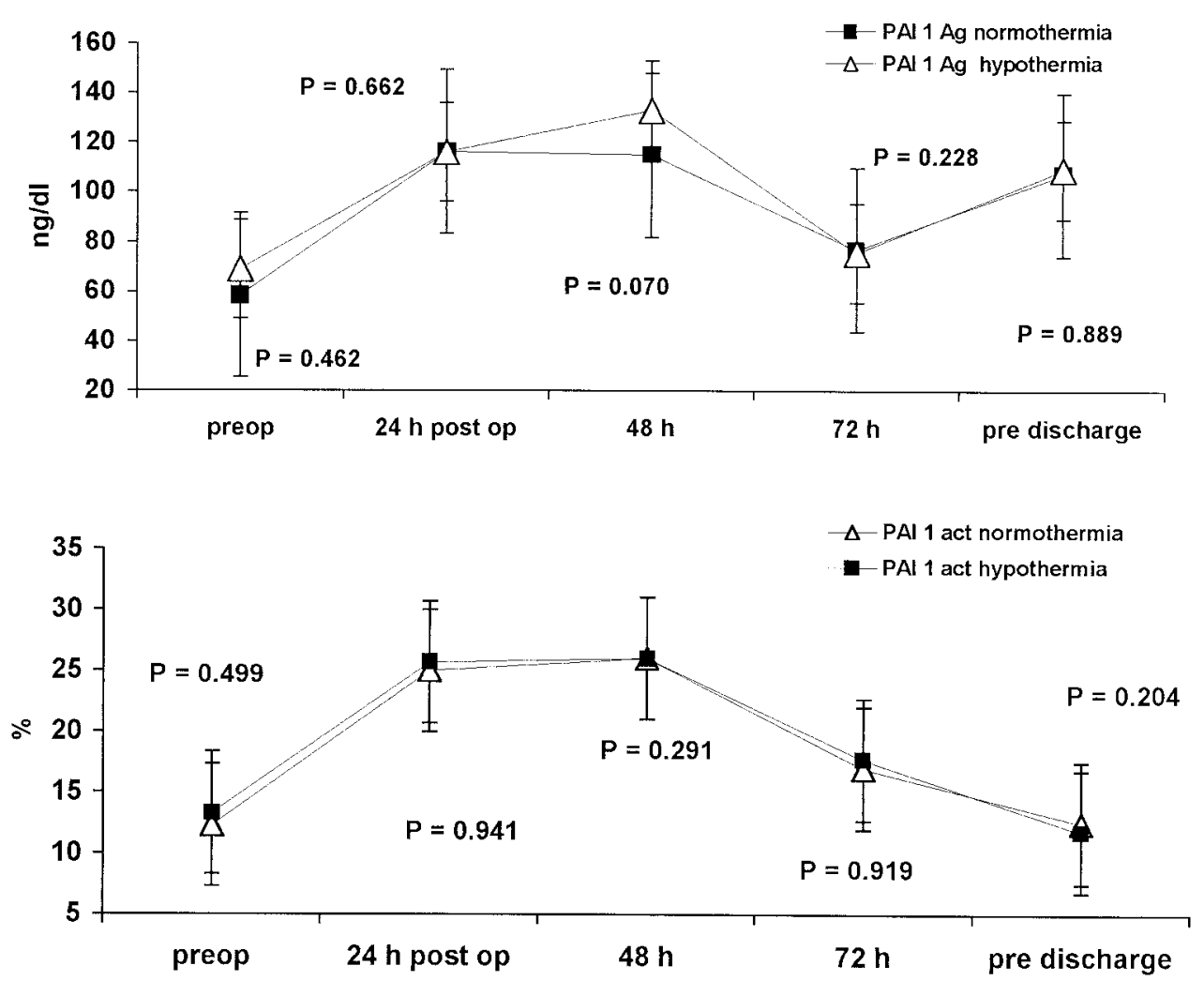

Figure 2. PAI-1 antigen and activity in the normothermic versus hypothermic series at the different sampling intervals.

concentrations declined slightly at 24 hours and then increased steadily until discharge (acting as an acute-phase protein), PTT showed only a trend toward prolongation at 24 hours, and INR values increased at 24 hours and returned to normal values 48 hours after the operation. Both PAI antigen and activity increased roughly 2 -fold at 24 to 48 hours after the operation (acting as an acute-phase reactant) and tended to almost normalize by the time of discharge.

No significant difference in the postoperative level of any of the measured variables at any time point was evident between the patients undergoing normothermic and hypothermic CPB (Figures 1-4). The mean postoperative concentrations of fibrinogen, CRP, IL-6, and PAI-1, as well as the platelet and WBC counts and the PTT and INR, were similar between the 2 groups at all sampling intervals.

\section{Discussion}

Despite its wide acceptance in common practice, the effective clinical benefits of NSP are far from being established. The majority of trials comparing normothermic and hypothermic CPB have demonstrated the similarities of the 2 strategies in terms of gross clinical indexes (mortality, morbidity, and length of postoperative stay), and no substantial systemic benefit related to the use of NSP has to date been definitely shown. In fact, the only advantages uniformly reported in almost all investigations are the earlier resumption of spontaneous cardiac activity (with consequent reduced need for electrical defibrillation and pacemaker use) and reduced systemic vascular resistance, ${ }^{3,4}$ both findings with limited clinical implications. Other differences (eg, better preservation of pulmonary function and reduced bleeding tendency) have inconsistently been described in different series or detected only in studies with limited statistical power. ${ }^{5}$

On the other hand, major concerns about the safety of NSP (mainly with regard to central nervous system protection) have been expressed by several authors. Although the early report of a greater incidence of stroke in patients operated on with normothermic CPB has not been confirmed in successive studies, ${ }^{6,7}$ we recently showed how normothermia is associated with a superior extension of brain damage and a worse neurologic outcome in patients who had an intraoperative stroke. ${ }^{8,9}$

The lack of major clinical benefits and the possibility of deleterious effects suggests caution with regard to the widespread adoption of NSP and warrants further investigation into its limits and advantages.

One of the presumed theoretic benefits of normothermia is a better maintenance of the cellular and humoral homeostatic processes (less efficient in hypothermic conditions), 

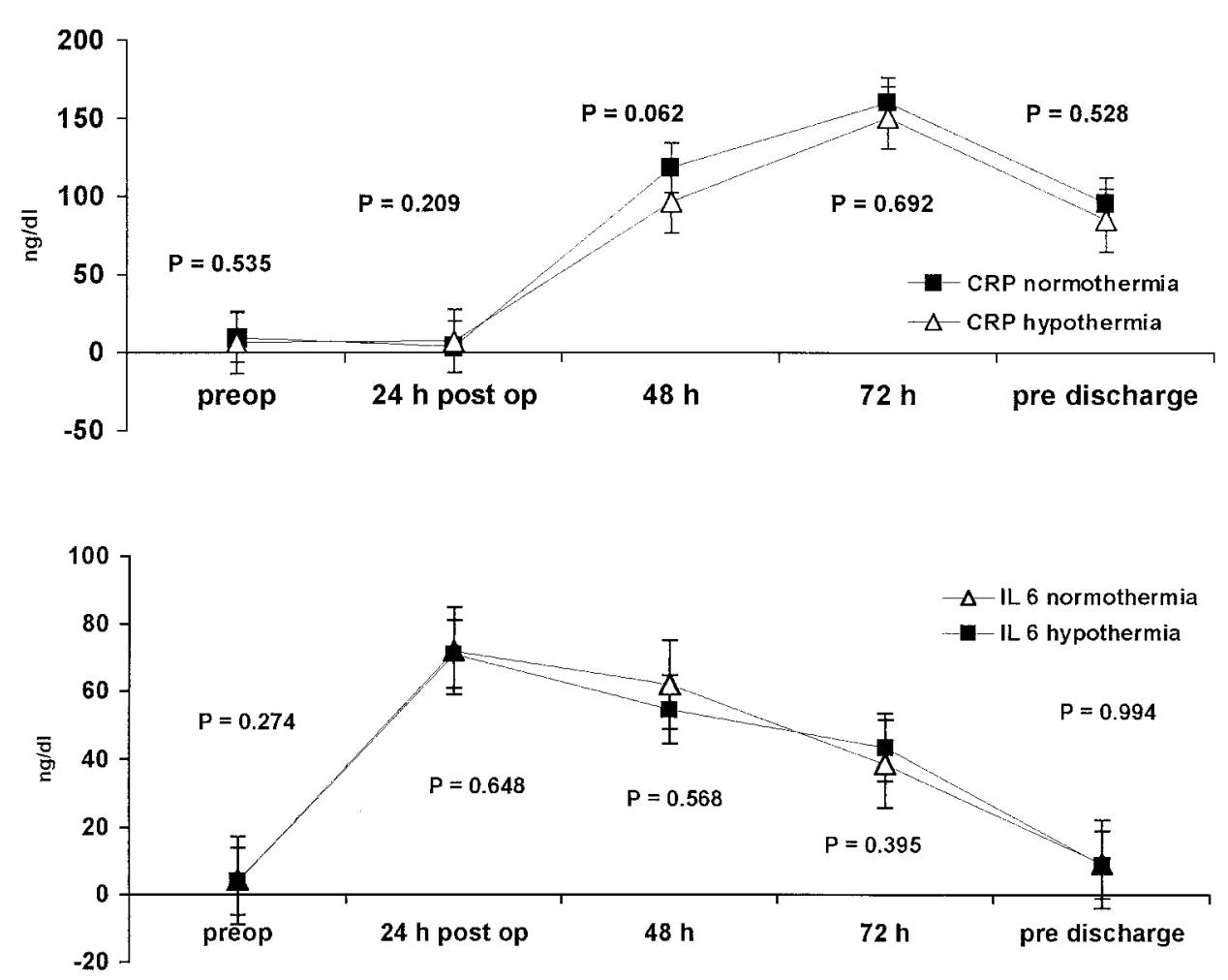

Figure 3. CRP and IL-6 levels in the normothermic versus hypothermic series at the different sampling intervals.

with consequent reduction of the systemic reaction to $\mathrm{CPB}$ and of CPB-induced multisystem organ damage. However, this theoretic assumption (which constitutes one of the main conceptual arguments in favor of NSP) has found only partial confirmation on the basis of objective data.

Indeed, the major studies investigating the relationship between extracorporeal circulation temperature and degree of activation of the inflammatory system have reported conflicting results, supporting in turn a proinflammatory ${ }^{10}$ or anti-inflammatory ${ }^{11,12}$ effect of NSP or the lack of major differences. ${ }^{13}$

Similar contradictions exist among the various investigations that have focused on postoperative indexes of activation of coagulation in patients operated on with hypothermic systemic perfusion versus NSP, with some series detecting a more pronounced alteration of the coagulation system after hypothermia ${ }^{14,15}$ and others describing no significant differences between the 2 temperatures. ${ }^{16,17}$

However, it must be stressed that the great majority of these studies were conducted on a limited number of patients and had a small number of sampling intervals and low statistical power. Moreover, most of them were not prospective randomized investigations and lacked rigorous criteria for the patients' inclusion and surgical management. In addition, the definition of both hypothermia and normothermia adopted by the different authors has been quite hetero- geneous, thereby hindering an accurate comparison of the results from the various groups.

In our series $\mathrm{CPB}$ temperatures did not significantly affect in-hospital clinical results or laboratory evidence of activation of the inflammatory and hemostatic systems in patients undergoing primary isolated CABG. Mortality, morbidity, number, and type of postoperative complications; bleeding tendency; and ICU and in-hospital stay were comparable between the 2 groups (although a small tendency toward a greater incidence of postoperative complications was registered in the hypothermic series). More interestingly, no difference between hypothermic and normothermic CPB was found for any of the measured hematic markers of activation of the inflammatory and hemostatic system (CRP, IL-6, WBC and platelet counts, PAI-1, fibrinogen, INR, and PTT) at any time point.

Although these laboratory data are in contrast with those reported by most of the other trials on this subject, methodological and statistical issues seem the most probable explanation for this difference. In fact, in contrast with the described limitations of the previous reports, our study included a prospective randomized design, rigorous enrollment criteria, and a uniform surgical protocol. Although the absolute magnitude of our patient population is not wide, and the possibility of a type II statistical error can not be completely excluded, the high complexity and cost of sen- 

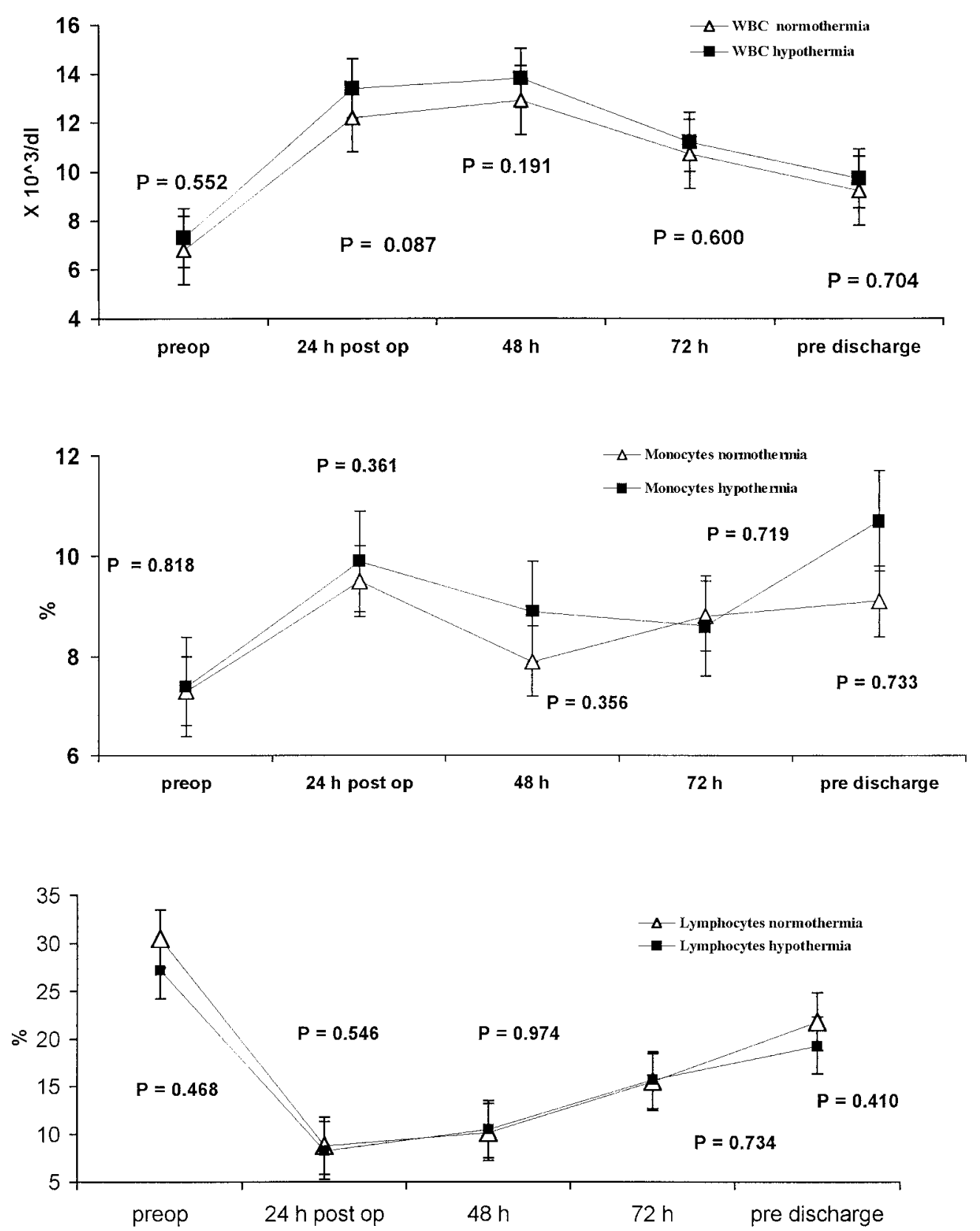

Figure 4. Platelet and white cell counts in the normothermic versus hypothermic series at the different sampling intervals.

sible biochemical markers in patients undergoing cardiac surgery obviously limit the enrollment of a larger cohort of patients in this type of investigation, and in fact, our study has a sample size far larger than those of all published series on this issue.

These considerations provide strong arguments in favor of the reliability of our observations and are very likely to render the reasons for the discrepancies between our observations and those already published.

It is also noteworthy that those clinical trials on hypo- thermic versus normothermic $\mathrm{CPB}$ with sufficient statistical power and with a rigorous study design failed to demonstrate any significant difference in the postoperative course (including mortality, incidence, type of complications, and length of ICU stay) and blood loss between patients operated on with warm or cold bypass. ${ }^{3,4}$ Even those clinical studies that specifically investigated the difference in the amount of postoperative blood loss between hypothermic and normothermic perfusion could not demonstrate any substantial reduction by using warm CPB. ${ }^{15,18-20}$ 

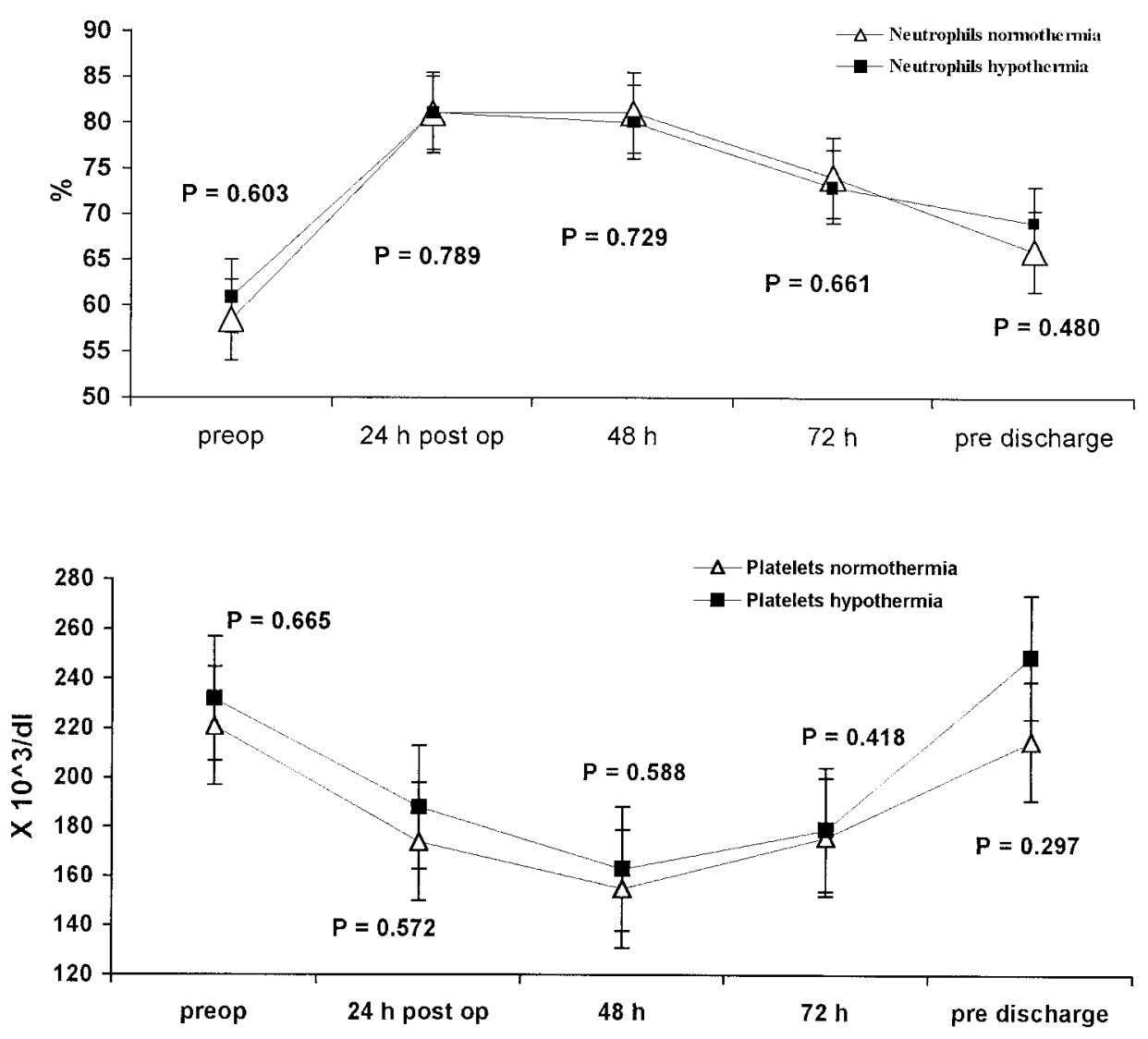

Figure 4. Cont'd.

Therefore, these sound clinical data seem to deny any measurable advantage of normothermia with regard to postoperative bleeding and provide a strong clinical correlate to our observations.

On this basis, it seems reasonable to assume that, in low-risk patients undergoing primary isolated CABG, NSP does not reduce (or increase) the extent of postoperative systemic inflammatory reaction or of activation of the hemostatic system. Although our study focused on highly selected cases and cannot definitely rule out possible differences in patients with organ dysfunction or those undergoing more complex cardiac operations, the almost identical magnitude of the systemic reaction to hypothermic and normothermic CPB (measured even using very sensible indexes) renders the hypothesis that these eventual differences are of any clinical relevance at least unlikely. These results, coupled with the reported concerns about neurologic safety with NSP, raise new doubts about the effective clinical advantages of normothermia in cardiac surgery and indicate the need for further careful investigation on the real pros and cons of normothermic CPB and on its specific effects on every organ and system.

We thank Dr Augusto Di Castelnuovo for statistical analysis; Drs Piergiorgio Bruno, Elisabetta Lapenna, and Filippo Santarelli for sample collection; and Concetta Amore for laboratory evaluations.

\section{References}

1. Lichtenstein SV, Astie KA, El Dalati H, Cusimano RJ, Panos A, Slutsky AS. Warm heart surgery. J Thorac Cardiovasc Surg. 1991; 101:269-74.

2. Sprengers ED, Kluft C. Plasminogen activator inhibitors. Blood. 1987; 69:381-7.

3. The Warm Heart Investigators. Randomized trial of normothermic versus hypothermic coronary bypass surgery. Lancet. 1994;343:55963.

4. Christakis GT, Koch JP, Deemar KA, Fremes SE, Sinclair L, Chen E, et al. A randomized study of the systemic effects of warm heart surgery. Ann Thorac Surg. 1992;54:449-59.

5. Ranucci M, Soro G, Frigiola A, Menicanti L, Ditta A, Candido G, et al. Normothermic perfusion and lung function after cardiopulmonary bypass: effects in pulmonary risk patients. Perfusion. 1997; 12:309-15.

6. Martin TD, Craver JM, Gott JP, Weintraub WS, Ramsay J, Mora CT, et al. Prospective, randomized trials of retrograde warm blood cardioplegia: myocardial benefit and neurologic threat. Ann Thorac Surg. 1994:57:298-304.

7. Craver JM, Bufkin BL, Weintraub WS, Guyton RA. Neurologic events after coronary bypass grafting: further observations with warm cardioplegia. Ann Thorac Surg. 1995;59:1429-34.

8. Gaudino M, Martinelli L, Di Lella G, Marano P, Schiavello R, Possati G. Superior extension of intraoperative brain damage in case of normothermic systemic perfusion during coronary artery bypass operations. J Thorac Cardiovasc Surg. 1999;118:432-7. 
9. Engelman RM, Pleet AB, Hicks R, Rousou JA, Flack JE III, Deaton $\mathrm{DW}$, et al. Is there a relationship between systemic perfusion temperature during coronary artery bypass grafting and extent of intraoperative ischemic central nervous system injury? J Thorac Cardiovasc Surg. 2000;119:230-2.

10. Menasché P, Peynet J, Larivière J, Tronc F, Piwnica A, Bloch G, et al. Does normothermia during cardiopulmonary bypass increase neutrophil-endothelium interactions? Circulation. 1994;90(Suppl):II-275-9.

11. Chello M, Mastroroberto P, Romano R, Ascione R, Pantaleo D, De Amicis V. Complement and neutrophil activation during cardiopulmonary bypass: a randomized comparison of hypothermic and normothermic circulation. Eur J Cardiothorac Surg. 1997;11:162-8.

12. Ohata T, Sawa Y, Kadoba K, Masai T, Ichikawa H, Matsuda H. Effect of cardiopulmonary bypass under tepid temperature on inflammatory reactions. Ann Thorac Surg. 1997;64:124-8.

13. Ohata T, Sawa Y, Kadoba K, Taniguchi K, Ichikawa H, Masai T, et al. Normothermia has benefical effects in cardiopulmonary bypass attenuating inflammatory reactions. ASAIO J. 1995;41:288-91.

14. Tonz M, Mihaljevic T, von Segesser LK, Schimid ER, Joller-Jemelka HI, Pei P, et al. Normothermia versus hypothermia during cardiopulmonary bypass: a randomized, controlled trial. Ann Thorac Surg. 1995;59:137-43.

15. Boldt J, Knothe C, Welters I, Dapper F, Hempelmann G. Normothermic versus hypothermic cardiopulmonary bypass: Do changes in coagulation differ? Ann Thorac Surg. 1996;62:130-5.

16. Engelman RM, Pleet B, Rousou JA, Flack JF III, Deaton DW, Pekow PS, et al. Influence of cardiopulmonary bypass perfusion temperature on neurologic and hematologic function after coronary artery bypass grafting. Ann Thorac Surg. 1999;67:1547-56.

17. Yau TM, Carson S, Weisel RD, Ivanov J, Sun Z, Yu R, et al. The effect of warm heart surgery postoperative bleeding. J Thorac Cardiovasc Surg. 1992;103:1155-63.

18. Mazer CD, Hornstein A, Freedman J. Platelet activation in warm and cold heart surgery. Ann Thorac Surg. 1995;59:1481-6.

19. Birdi I, Regragui I, Izzat MB, Bryan AJ, Angelini GD. Influence of normothermic systemic perfusion during coronary artery bypass operations: a randomized prospective study. J Thorac Cardiovasc Surg. 1997; 114:475-81.

20. Stensrud PE, Nuttall GA, de Castro MA, Abel MD, Ereth MH, Oliver WC Jr, et al. A prospective, randomized study of cardiopulmonary bypass temperature and blood transfusion. Ann Thorac Surg. 1999; 67:711-5.

\section{Appendix}

\section{Definitions}

For the purpose of this report, the following definitions were used:

- Carotid disease: Monolateral or bilateral carotid stenosis of $70 \%$ or greater demonstrated by means of pre- operative Doppler echocardiography and carotid angiography.

- Myocardial infarction: Diagnosed on the basis of echocardiographic evidence of regional hypokinesia or dyskinesia, MB fraction of greater than $4 \%$ of the total hematic level of creatine kinase concentration, and appearance of new Q waves on the electrocardiogram.

- Renal insufficiency: Postoperative increase of the serum creatinine level of $2 \mathrm{mg} / \mathrm{dL}$ or greater with respect to the preoperative level.

- Respiratory insufficiency: $\mathrm{PaO}_{2}$ of less than $60 \mathrm{~mm} \mathrm{Hg}$ in current air.

- Intraoperative stroke: New focal neurologic deficit or coma associated with computed tomographic demonstration of recent ischemic cerebral lesion that became evident at the moment of the awakening of the patient from anesthesia and lasted for more than 24 hours.

- Postoperative stroke: New focal neurologic deficit or coma associated with computed tomographic demonstration of recent ischemic cerebral lesion and lasting for more than 24 hours that became evident after a normal awakening of the patient from anesthesia and a normal postoperative neurologic status.

- Minor postoperative complications: Renal insufficiency, mechanical ventilation for more than 24 hours, respiratory insufficiency, inotropic support for more than 24 hours, need for blood transfusions, and revision for bleeding.

- Major postoperative complications: Death, stroke, shock, sepsis, myocardial infarction, and reoperation.

- Hemorrhagic postoperative complications: Need for blood transfusions and revision for bleeding.

\section{Routine Blood Assay Methods}

Platelet, WBC, neutrophil, lymphocyte, and monocyte counts were measured automatically (Technnicon H3 RTX, Bayer, Germany). Measurements of prothrombin time (expressed as INR) and activated PTT were also carried out automatically (Elektra 1800, MLA). 